\title{
ARARIPE JÚNIOR: UM TAINE ÀS AVESSAS?
}

\author{
Luiz Roberto Velloso Cairo
}

RESUMO: This essay discusses the influence of Hippolyte Taine in Araripe Júnior's criticism based on a thorough research of his works.

PALAVRAS-CHAVE: comparativismo, crítica literária, história literária, Araripe Júnior, Hippolyte Taine, Émile Hennequin.

No exercício da atividade crítica, Araripe Júnior, um dos críticos brasileiros mais importantes do Século XIX, assume como fundamental para a sua formação a influência das idéias de Hippolyte Taine. Influência essa que é reconhecida por José Veríssimo e Sílvio Romero, seus contemporâneos e pelos críticos e historiadores da literatura brasileira de um modo geral.

Em 1911, ao publicar, em livro, o ensaio Ibsen, pela Livraria Chardron, de Lello e Irmãos Editores, do Porto, em Portugal, Araripe Júnior reproduz o Prefácio à primeira versão do trabalho, intitulada $A$ estética de Poe, publicada na Revista Brasileira, em 1895, com a seguinte observação:

"Embora decorridos catorze anos, pouco tenho mudado substancialmente. Estes ensaios, publicados em várias épocas, conforme se vê da data lançada em cada artigo, mostrarão ao leitor atento a evolução do meu critério literário". (Araripe Júnior, 1970, p.35)

Ibsen, na verdade, um de seus últimos escritos, uma vez que faleceu em 1911, trata-se de um work in progress, iniciado em 1895 e concluído em 12 de setembro de 1909. Um ensaio em que, pelo seu caráter progressivo, estão presentes muitas das inquietações do crítico e que se torna ainda mais curioso, pelo fato de o autor prefaciá-lo com uma confissão do que seria o seu método crítico, e, não contente apenas com isso, ao invés de redigir um novo texto, reproduz as declarações feitas

Universidade Estadual Paulista - Assis 
catorze anos antes - o prefácio é datado de 10 de julho de 1909 - em resposta a José Veríssimo, reforçando assim as principais idéias que acompanham a sua trajetória crítica. Nela, a presença de Taine é quase uma profissão de fé.

Como a História, ao se escrever, conferiu a este prefácio um sabor de testamento do crítico, convém transcrever o seguinte trecho:

"O Sr. José Veríssimo assinalou a influência de Taine como decisiva nos meus processos de crítica. Não o nego; e declaro até que, se não existissem os trabalhos do autor da História da Literatura Inglesa, é bem provável que eu ainda hoje estivesse jungido ao sistema das causas fortuitas. Essa influência que me foi extremamente benéfica, porquanto corrigiu algo de místico, que havia no meu temperamento de escritor, não me avassalou; todavia, por mais entusiasmo que gerassem no meu espírito, as leis de estética, analisadas pelo mestre, encontram em mim um sóbrio e cuidadoso aplicador. $\mathrm{O}$ método fortaleceu-me e ensinou-me, primeiro que tudo, a estudar. Pois bem, esse mesmo método habilitou o discípulo a compreender os próprios defeitos daquele insigne professor". (1970, p.33)

A marca de Taine, no discurso crítico de Araripe Júnior, é muito forte e a famosa tríade - raça, meio, momento - perpassa toda sua obra. Tendo optado pela predominância do meio, principalmente, no caso dos dois primeiros séculos de Brasil, é a partir desta escolha que constrói o princípio da obnubilação brasílica presente nos ensaios sobre Aluísio Azevedo, José de Alencar e Gregório de Matos.

Por obnubilação brasílica, entende-se a transformação por que passavam os europeus ao atravessarem o oceano Atlântico e a sua conseqüente adaptação ao meio físico e ao ambiente primitivo. Essa transformação ocorreu também a nível das idéias que, ao serem transportadas, adaptaram-se ao meio ambiente, adquirindo uma certa originalidade, que se traduziu no que Araripe Júnior chamou de estilo tropical:

"O estilo, nesta terra, é como o sumo da pinha, que, quando viça, lasca, deforma-se, e, pelas fendas irregulares, poreja o mel dulcíssimo, que as aves vêm beijar; ou como o ácido do ananás do Amazonas, que desespera de sabor, deixando a língua a verter sangue, picada e dolorida". (1960, p.70-1)

Como consequência, a importação dos modelos gerou uma nova fórmula, conforme se pode observar em relação ao naturalismo: 
"O naturalismo brasileiro é a luta entre o cientificismo desalentado do europeu e o lirismo nativo americano pujante de vida, de sensualidade.

"É da limitação apenas das tendências dessa mestiçagem, reconhecida por todos que têm estudado o problema do nosso nacionalismo; é dessa, e não de outra limitação, que tiraremos toda a nossa força, toda a nossa segurança, e riquezas literárias.

"Um realismo quente, em oposição a um realismo decadente, frio; a realidade, como mais apropriado entendam". (1960, p.72)

Posteriormente, ao escrever sobre o psicologismo de Raul Pompéia, no ensaio sobre o romance $O$ Ateneu, seu discurso começa a apresentar uma enorme afinidade com as idéias de Émile Hennequin.

O conhecimento da obra de Hennequin, ex-discípulo de Taine, estimula Araripe Júnior a prosseguir na sua fidelidade a Taine, pois toma consciência de que muitas reformulações propostas pelo jovem crítico francês já tinham sido por ele feitas no ensaio sobre José de Alencar, de acordo com o que se depreende do prefácio à $2^{\circ}$ edição deste ensaio, datado de 19 de fevereiro de 1894:

"O que o Dr. Viveiros de Castro não quis enxergar foi aquilo justamente que mais trabalho me havia custado, - a história da evolução do espírito artístico de José de Alencar e, paralelamente, a morfologia, a filiação e a transformação dos caracteres dos personagens dos seus romances. Nisto residia essencialmente a alma do livro; relendo-o hoje, depois de doze anos, não o renego, apesar das grandes modificações operadas em meu espírito posteriormente, por novos estudos e pela meditação das obras de arte atuais. Não o renego, não só por esse motivo, mas também porque vejo que, sendo o perfil o primeiro trabalho sobre um autor nacional, que se escreveu no Brasil, aplicando os métodos de H. Taine, antecipava alguns processos depois postos em prática pelo malogrado $\mathrm{E}$. Hennequin, discípulo do grande crítico francês e, ao mesmo tempo, modificador, no que ele chamava estopsicologia, dos excessos doutrinais do autor da História da Literatura Inglesa." (1958, p.132)

Vale ressaltar que Hennequin, mesmo tendo reformulado as idéias de Taine, nele reconhece papel de destaque no que se refere à crítica científica:

"Foi Taine quem mais avançou no sentido da crítica científica pura. Desde o aparecimento da História da Literatura Inglesa, nada digno de menção se produziu a dentro deste método." (Hennequin, 1910, p.17) 
Esse crítico francês, falecido aos vinte e oito anos, é uma presença na obra crítica de Araripe Júnior pelo menos a partir de 24 de setembro de 1889, quando, no artigo "Estética e eletricidade", publicado no jornal Novidades, do Rio de Janeiro, é transcrito seu conceito de obra literária:

"A obra literária é um conjunto de frases escritas ou faladas, com o fim de produzir, na alma dos leitores ou ouvintes, uma emoção especial, a emoção estética, que tem o seguinte particular: não se traduz por atos, pois ela é o fim de si mesma." (1960, p.192)

As idéias de Hennequin estão presentes também em outros críticos brasileiros, além de Araripe Júnior. Ao afirmar isto, não quero dizer que ele tivesse sido o grande modelo da crítica realista brasileira, pois tenho consciência da dimensão do crítico menor que ele foi, mas justamente em função da sua condição secundária é que me surpreendi ao encontrar grandes afinidades entre o seu discurso e, principalmente, o de Araripe Júnior.

Essas afinidades provocam no leitor um estranhamento no que se refere principalmente às idéias de Taine, tanto assim que Sílvio Romero chega a fazer a seguinte observação no ensaio Da crítica e sua exata definição:

"Esse jovem, cujo merecimento era grande, mas não deve ser exagerado, como é hábito em certos círculos, procurou sistematicamente colocar-se em pontos de vista opostos ao do autor da História da Literatura Inglesa. Poderia, por isto, ser chamado um Taine retourné.

"Este procurava tornar na crítica, quero dizer na estética, salientes os fatores mesológicos, etnográficos e fisiológicos; o autor d'A Crítica Científica procura batê-lo nestes pontos e substituir no estudo dos autores aqueles elementos explicativos por considerações puramente psicológicas, sociais e estéticas.

"Taine procurava mostrar a gênese, a formação do gênio dos escritores; Hennequin tentava de preferência mostrarlhes a influência, procurando ver quem os lia, quem os admirava.

"Era o tainismo às avessas." (Romero, 1980, p.331)

Não concordo com Sílvio Romero, quando ele diz tratar-se de um tainismo às avessas, pois vejo muito mais em Hennequin um Taine revisitado. Sua gratidão ao mestre é uma constante, uma vez que reconhece ter sido Taine quem mais avançou no sentido da crítica científica. Aliás, este é o ponto de afinidade maior entre Araripe Júnior e Hennequin. Ambos sentiram a necessidade de revisar e dar continuidade às idéias de Taine. 
No prefácio a Ibsen, a que me referi, anteriormente, Araripe Júnior mostra o que sempre combateu em Taine e como procurou aprimorar os seus procedimentos:

"Para que o método do mestre, dizia a mim mesmo, não se torne inútil e banal, é indispensável que haja sinceridade; que se não abuse do instrumento de demonstração; que finalmente à aplicação desse instrumento, que é tão exato como pode ser exato o teodolito, preceda um critério filosófico, com quem afirma uma ontologia positiva e uma ética clara e de utilidade prática. Ora, sob esses dois pontos de vista, o autor da História da Literatura Inglesa estava muito longe de interessarme. As suas conhecidas tendências pessimistas, o seu determinismo seco e a sua falta de lirismo, sem equivalentes de ordem moral e prática na vida humana, contrariavam a cada instante as tendências opostas, que constituem o fundo de minha natureza. Daí originou-se para mim um combate contínuo no sentido de descobrir outro ponto de apoio, sem contudo perder a riqueza dos processos tainianos." (1970, p.334)

Quando Araripe Júnior escreveu o ensaio sobre Gregório de Matos, o contato com Hennequin já havia sido feito, e o ensaio sobre $O$ Ateneu, de Raul Pompéia já havia sido escrito. Estes fatos contribuem para que se encontre uma visão de Taine diferente daquela que está no estudo sobre José de Alencar.

Ao expor suas idéias, em A Crítica Científica (1888), Hennequin propõe uma distinção entre a crítica literária e a crítica científica.

A crítica literária se aproxima do que se costuma chamar de resenha literária, escritos que "se consagram, na realidade, a criticarem, a apreciarem, a pronunciarem-se categoricamente acerca do valor desta ou daquela obra, livro, drama, quadro ou sinfonia" (1910, p.5-6); enquanto que a crítica científica estaria mais próxima do ensaio já que seriam escritos que

"procuram outro objetivo, tendem para deduzirem dos caracteres particulares da obra alguns princípios de estética, ou a existência de determinado mecanismo cerebral no autor, ou ainda uma condição definida do conjunto social em que se formou, explicando por leis orgânicas ou históricas as emoções que suscita e as idéias que exprime." (1910, p.6)

A crítica científica seria a análise da obra de arte

"com o intuito de encontrar indicações estéticas, psicológicas e sociológicas, trabalho de ciência pura, em que o autor se dedica a extrair causas dos fatos, leis dos fenômenos, estudando tudo sem parcialidade e sem predileções." (1910, p.6) 
A crítica científica, estopsicologia, terminologia próxima da estoliteratura, encontrada em Sílvio Romero no ensaio Da crítica e sua exata definição (1980, p. 316-44) prevê três tipos de análise da obra, uma vez que parte de considerações de estética, recorre à psicologia e apela para a sociologia.

Do ponto de vista da análise estética, a obra literária seria

"um conjunto de frases escritas ou faladas, destinadas por imagens de toda a espécie, quer muito vivas e precisas, quer mais vagas e ideais, a produzirem nos leitores ou auditores uma emoção especial, a estética, que tem a particularidade de não se traduzir em atos, encontrando em si mesma o seu fim." (1910, p.21)

Num enfoque psicológico, diz o crítico:

"A obra dum artista é o sinal compreensível do seu espírito, o qual, como humano, é constituído pelo mesmo mecanismo geral de sensações, imagens, idéias, emoções, volições, impulsões motrizes e retardatárias, da generalidade das inteligências humanas." (1910, p.57)

Convém observar que Hennequin manifesta uma preocupação com a recepção da obra que pouco tem a ver com os princípios da Teoria do Efeito, de Wolfgang Iser, e os pressupostos da Estética da Recepção, de Hans Robert Jauss.

"Na realidade, um livro, por exemplo, é primeiramente o que é, mas também, em seguida, é a obra dum homem e a leitura de muitos e, no remontar do livro ao autor e aos admiradores é que consiste propriamente a crítica científica. Uma obra de arte pode dar-nos indicações sobre o seu produtor, sobre as faculdades de que ele seja a imagem e sobre os seus admiradores de cujo gosto a obra é ainda indicadora. As primeiras indicações dizem respeito à psicologia individual, as segundas à psicologia social, sendo as primeiras aquelas que primeiramente vamos estudar." (1910, p.44)

Esta preocupação, conduzindo-o ao conhecimento do repertório do artista que produziu a obra, do público que a consumiu e da época na qual foi produzida e consumida, conseqüentemente, leva-o a pensar no problema de como a realidade do artista e/ou do mundo exterior se reflete na obra, em função daquelas obras em que o artista se desvia da realidade. Daí ter pensado em obras autobiográficas, onde facilmente se refletem as emoções do artista; obras de artistas parnasianos, onde qualquer intervenção individual, qualquer exuberância, qualquer 
confusão é eliminada; obras de artistas que imitam outros, obras de escritores mercenários, de contistas para crianças, dos folhetinistas que escrevem para uma determinada classe da sociedade, dos artistas preocupados em agradar ao público sem se importar com seu agrado pessoal.

Tudo isso já constitui a passagem para o enfoque sociológico e é o próprio Hennequin quem diz:

"Encaramos a obra de arte nas relações com a inteligência do autor; carecemos agora de estabelecermos as suas relações mais longínquas com certos grupos de homens que, em virtude de diversas considerações, podem ser julgados semelhantes e análogos do artista produtor." (1910, p.63)

Partindo de Taine que primeiro estabeleceu a relação entre a obra e o conjunto social de que é contemporânea, refuta-o:

"Em resumo, não obstante a obra de Taine, vê-se que é impossível estabelecer uma relação direta entre uma sociedade e os artistas que a ilustram, considerando estes como independentes de causas comuns. Estas causas, em todo o caso, não podem ser nem a raça, nem o meio, nem o habitat, por isso que a essência duma causa é atuar sempre e a ação destes três princípios é variável." (1910, p.81)

A sua genial sacada, porém, foi deslocar o foco de observação do artista que produziu a obra para o público que a consome.

"Admitido, pois, que um artista não depende essencialmente do seu meio, da sua raça, do seu país e que, por essas causas, não podemos assimilá-lo aos seus compatriotas e aos seus contemporâneos ou, por outros termos, que não há causa comum entre estes e aquele, devemos fazer um rodeio para obtermos da estética dados sociológicos. Devemos dirigirmo-nos não ao artista, mas ao seu produto; devemos ter em consideração não os que o rodeiam, mas os admiradores das suas obras.

"Toda a obra de arte, se por um extremo toca no homem que a criou, toca pelo outro no grupo de homens que emociona." (1910, p.85)

Dentro deste raciocínio, Hennequin estabelece a seguinte lei:

"Uma obra de arte só exerce efeito estético sobre as pessoas de que os caracteres dessa obra representam particularidades mentais; ou, em menos palavras, uma obra de arte só emociona aqueles cujo sinal é." (1910, p.91-2)

Mais adiante reformulada: 
"(...) uma obra só terá efeito estético nas pessoas que possuam uma organização mental análoga àquela que serviu para criar a obra e que dela pode ser deduzida." (1910, p.92)

Feita esta exposição dos principais tópicos da teoria de Hennequin, é preciso dizer que, apesar de ter uma proposta de uma crítica científica abrangendo três tipos de enfoques, ou obedecendo a sua terminologia, três tipos de síntese: a estética, a psicológica e a sociológica, na prática, aparece a literatura, a obra literária, como fornecedora de farto material para auxiliar o conhecimento científico da estética, psicologia e sociologia. Na verdade, a crítica científica da literatura era um instrumento auxiliar bastante eficaz para as demais ciências.

A crítica científica visava muito mais auxiliar as demais ciências do que conhecer o objeto de seu estudo: a literatura. Aos olhos de hoje, esta seria, aparentemente, uma das falhas do cientificismo presente também nos escritos de Araripe Júnior. Ao estudar a obra literária, buscava-se desvendá-la através do conhecimento da personalidade do autor e da sociedade que a produziu e a consumiu. Esse acabava sendo, talvez, consciente ou inconscientemente, o objetivo primeiro da crítica. Não cabe, porém, a cobrança de uma crítica literária cuja meta prioritária fosse dar conta da obra para, posteriormente, também auxiliar a ciência e demais ramos do conhecimento humano. Isto vai configurar-se algum tempo mais tarde. Era inviável para Hennequin, assim como para os críticos brasileiros, este caminho, pois não era a preocupação de sua época.

Na obra crítica de Araripe Júnior, além das marcas de Taine e das afinidades com a releitura proposta por Hennequin, índices de leituras de outros críticos são percebidos no seu modo de aplicar o método do mestre.

Nos vários escritos sobre Raul Pompéia, é curioso observar que suas constantes idas e vindas a este autor, levaram-no a uma aproximação desse romancista com as idéias de John Ruskin, pois via uma certa afinidade com o crítico inglês:

"Raul Pompéia foi quase um pré-rafaelista.

"Nunca lera Ruskin; mas o seu temperamento artístico, as suas tendências para as artes plásticas, contatos com as obras de arte francesa remodeladas por Maurice Barrès, de quem era apaixonadíssimo, fizeram-no advinhar toda a estética daquele grande crítico inglês.

"Para o autor de $O$ Ateneu, a obra de arte era simplesmente uma METAMORFOSE. 


\begin{abstract}
"Ainda não esqueci uma palestra que tivemos e cujo tema foi o processo metamórfico da imaginação. Puro ruskianismo." (1963, p.259)
\end{abstract}

Essas idas e vindas à obra de Raul Pompéia levaram-no também a diferentes modos de ver o Simbolismo. Sua visão do Simbolismo já se altera de maneira significativa no decorrer do ensaio sobre $O$ Ateneu. Se no início há um crítico intolerante em relação aos decadistas, à medida em que vão sendo publicadas, no jornal Novidades, as diversas partes do ensaio, vai surgindo um crítico mais condescendente que não será mais o mesmo em Movimento Literário do Ano de 1893, nem em A Literatura do Futuro, nem em outros escritos em que o Simbolismo é enfocado.

Vale observar que o simples fato de Araripe Júnior publicar seus ensaios em jornais e revistas, em períodos relativamente longos, devia proporcionar-lhe um constante repensar de pontos de vista. Isto talvez explique a variação de enfoque de um mesmo problema, muitas vezes num mesmo trabalho.

O estranhamento causado pela obra de Raul Pompéia em relação ao cânone literário de seu contexto é bastante benéfico para o crítico Araripe Júnior. Creio mesmo que a sua condescendência para com os simbolistas tivesse, em parte, sido resultado do impasse criado pela obra de Pompéia. Araripe Júnior via que Pompéia fugia do pessimismo de Zola, percebia semelhanças no seu estilo com os decadistas, mas se recusava a enxergá-lo como tal. O Simbolismo feria os princípios da Ciência e Raul Pompéia, segundo ele, não poderia transgredi-los. Aí estava a grande resistência de Araripe Júnior, o seu método era calcado nos princípios da crítica científica, da estopsicologia, como a denominava Hennequin. Era dentro desses princípios que ele trabalhava, é por isso que a descoberta de Ruskin, com a valorização da imaginação e a tentativa de combinar naturalismo e simbolismo, veio abrir-lhe o horizonte para a condescendência que o levou bastante próximo à aceitação do Simbolismo.

O Simbolismo era algo de futuro para quem convivia com o presente da Ciência, de certo modo, uma ruptura com a tradição romântica com a qual convivera no início de carreira.

Sua visão da tradição romântica já constituía algo de novo naquele contexto, já apresentava uma ruptura. Os princípios científicos levavamno a um modo de ver o Romantismo e os movimentos anteriores diferente dos críticos que o antecederam. Sua visão não era uma visão romântica, mas realista. Nela havia uma busca de princípios que explicassem a causa dos fenômenos que se observavam. A observação já era uma necessidade que se impunha no seu estilo de ler as obras com um princípio científico e essa observação era essencial para que pudesse estabelecer os parâmetros de comparação entre as obras literárias nacionais e o seu vasto repertório. 
Convém aqui abrir um parêntese para dizer que Araripe Júnior fazia, em alguns momentos, incursões pela Literatura Comparada, e isso ocorria, com uma certa naturalidade, quando incorporava a sua leitura da literatura européia e norte-americana à leitura que fazia da literatura brasileira: Walter Scott e James Fenimore Cooper em Alencar, Hugo e Zola em Aluísio Azevedo, Poe, Mallarmé, René Ghil em Raul Pompéia, etc. Araripe Júnior, nesse sentido, era um leitor que se expunha ao expor sua leitura, e nessa exposição aparecia também a leitura que os críticos nacionais e estrangeiros faziam das obras em estudo. E é nesse mostrar-se que constatei, por exemplo, a presença no seu discurso crítico do evolucionista inglês Herbert Spencer.

Basta folhear o ensaio Raul Pompéia. O Ateneu e o romance psicológico, onde o escritor é comparado ao maquinista e a obra literária à locomotiva para que isto se confirme. Aliás, aí se dá a fusão de Hennequin e Spencer. À idéia da obra de arte como uma máquina de provocar emoções (Hennequin), acrescenta-se o fato de a mesma ser uma locomotiva (Spencer). De acordo com Richard Graham, em GrãBretanha e o início da modernização no Brasil, Spencer exercia grande atração entre os pensadores brasileiros pelo seu interesse singular pelas estradas de ferro, "como parte importante do sistema orgânico de uma sociedade moderna" (Graham, 1973, p. 248) 'Por causa da invenção da locomotiva, dizia Spencer, 'o organismo social havia-se tornado mais heterogêneo'" (1973, p.248-9) Além disso, Spencer fascinava os intelectuais brasileiros pela sua "habilidade em sintetizar todo conhecimento e fazê-lo inclinar-se ante a ciência natural." (1973, p.249)

Esta busca da síntese já aparece nos primeiros escritos de Araripe Júnior. Logo no início da conferência O Papado (1874), ele diz:

"Sempre busquei os fatos separados de toda e qualquer preocupação, e só depois de compendiados e formada a síntese, foi-me lícito procurar as leis que porventura os regem. Desse modo, a história não se me impôs pelos nomes de seus autores ou daqueles em nome de quem a escreveram; nela não enxerguei senão um campo vasto de explorações, um mundo desconhecido, onde se devia encontrar os dados certos de todas as tendências do homem em sua vida complexa e terrena." (1958, p.71)

$\mathrm{Na}$ trajetória que fiz pela obra crítica de Araripe Júnior, pude observar que as influências mais marcantes no seu discurso crítico vieram de Taine, Spencer, Ruskin e Hennequin. Esses pensadores perpassam a sua obra, mas foi em Hennequin que percebi a afinidade quase total no que se refere à revisão do pensamento taineano.

No prefácio a Ibsen, resgata-se a fidelidade de Araripe Júnior a Taine, mas não simplesmente fidelidade cega, aceitação do que havia de positivo, e o mais importante, consciência das limitações, o que o levou 
não à rejeição, mas à revisão e evolução de suas idéias, na direção de manter vivo e redimensionar o pensamento do mestre.

Um Taine retrouvé, não às avessas, como enxergava Sílvio Romero a revisão da crítica de Taine feita por Hennequin, muito próxima à de Araripe Júnior que prosseguiu essa tarefa.

Revistas, as idéias de Taine sobrevivem nas leituras de Araripe Júnior que, lucidamente, buscou entender as várias tendências críticas de seu tempo.

\section{BIBLIOGRAFIA}

ARARIPE JÚNIOR, Tristão de Alencar. Obra crítica de Araripe Júnior. (Dir. Afrânio Coutinho) Rio de Janeiro, MEC-Casa de Rui Barbosa, v. I, 1958; v. II, 1960; v. III, 1963: v. IV, 1970.

GRAHAM, Richard. Grã-Bretanha e o início da modernização no Brasil 1850-1914. Traduzido por Roberto Machado de Almeida. São Paulo, Brasiliense, 1973.

HENNEQUIN, Émile. A crítica científica. Traduzido por Agostinho Fortes. Lisboa, Editora da Tipografia de Francisco Luiz Gonçalves, 1910.

ROMERO, Sílvio. História da literatura brasileira. Rio de Janeiro, José Olympio; Brasília, INL-MEC, 1980. 